\title{
Evolvement Trace of Standing Postures of Human Bodies of Ancient Greek Sculptures \\ Bingnan Feng
}

Art College, Southwest University for Nationalities, Chengdu, 610000, China

Keywords: ancient Greek sculptures, artistic characteristics, contextualization, human body, standing posture

\begin{abstract}
The unique charm of ancient Greek sculptures is that it can reflect the people's persistent pursuit of artistic expression. The standing postures of human bodies of ancient Greek sculptures showed a dull feeling in the early orientalizing period. Gradually, it evolved into the perfect fusion of standing postures and story lines in the late Hellenistic period. It is not only the unified development of standing postures of human sculptures and the contextualization, but also the progress of the artists' thought, which reflects the deeper understanding of the structure of the human body.
\end{abstract}

\section{Religious phenomenon and early posture of Greek sculptures}

From the view of early age, the sculptures in the era of geometric pottery were often treated as funerary offerings and sacrifices. They begin to be rich in human form, no longer absolute abstraction. We can see in the Figure 1, the torso legs in front of us were upright posture and not clever, but the features of the people became concrete. We can see the statue of human body is slowly from abstract to concrete transformation. In the 700 B. C., the statue of the human body is no longer so flat compared to the previous statue. It becomes more three-dimensional (Figure 2). We can also see that the human body of the statue of the kind of slender legs have been replaced by more realistic proportions. His left foot slightly bent forwardwith a dynamic posture and the arms at his side clenched. The characterization of the characters in the face, with some idealized modifications in reality. The nude male statue (Figure 3 ) of the sixth century BC is a form of round sculpture. The ancient Greek sculpture was restricted by certain social ideology. The characters appeared dull and lifeless. The ancient Greek sculpture in this period began to focus on how to express the characters themselves.
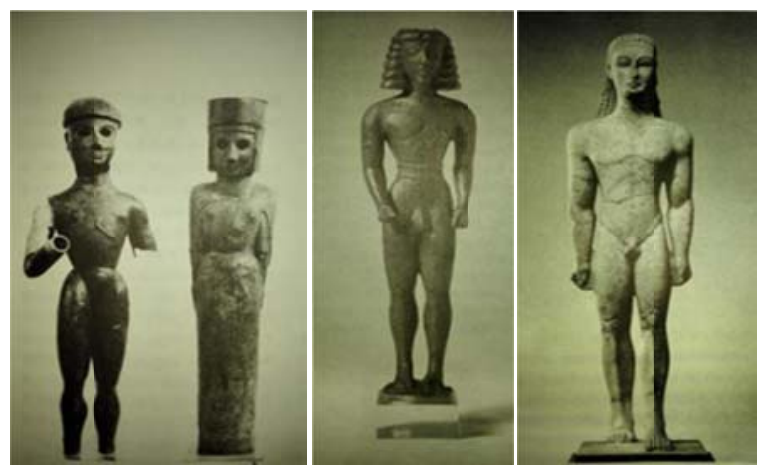

Fig.1, Fig. 2 and Fig. 3 


\section{Secular life and inheritance and innovation of postures of Greek sculptures}

In the middle of the ancient Greek sculpture, part of the sculpture still maintained the original attitude, although somewhat different. The sculptor has not completely break through the traditional position: take a foot stand. The Archaic period of human statues still put a serious expression, but after that, the sculptor who was with the creation of new exploration, they tried to erect the body center of gravity moved to the foot, with the characters in real life rich and dynamic.As the end of the Archaic period boy, Kerry Tiiu Boy (Figure 4) also opened the beginning, of organic expression of body action. He presented is a new type of cable station position. This is an improvement on the original position. His right foot bent forward,not loading all the weight on the left leg, at the same time, with the change of attitude. The statue also appeared in the dynamic on the horizontal axis, the statue of the lower right hip, shoulder slightly tilted, the head side, the body has a certain sense of curve. It can be seen that the sculptor is trying to think how to show a strong dynamic sculpture of the human body. Spear (Figure 5) is the embodiment of the perfect proportion of men's statue, which is a vibrant, healthy young man's image. The battle of Lapithae and Centaur appeared in the south wall column of Parthenon Temple in Athens (Figure 6). The two characters collide, poses an onslaught of tilt posture. The statue is a bold idea between the columns. Pull over, jump forward in the framework of the Thai horizontal rectangular feet, back, abdomen and turn slightly taut body of interpretation should be out of character attitude inclined station posture, and the Centaur backward attitude also deepened this view. The classical period in the temple statue are almost out of the cable station posture, scene and statue standing has gradually fused together, although only one of the scenes of the expression. It is obvious to see the posture began to be given action. At the same time, it laid the foundation for a single scene to the direction of the statue development.

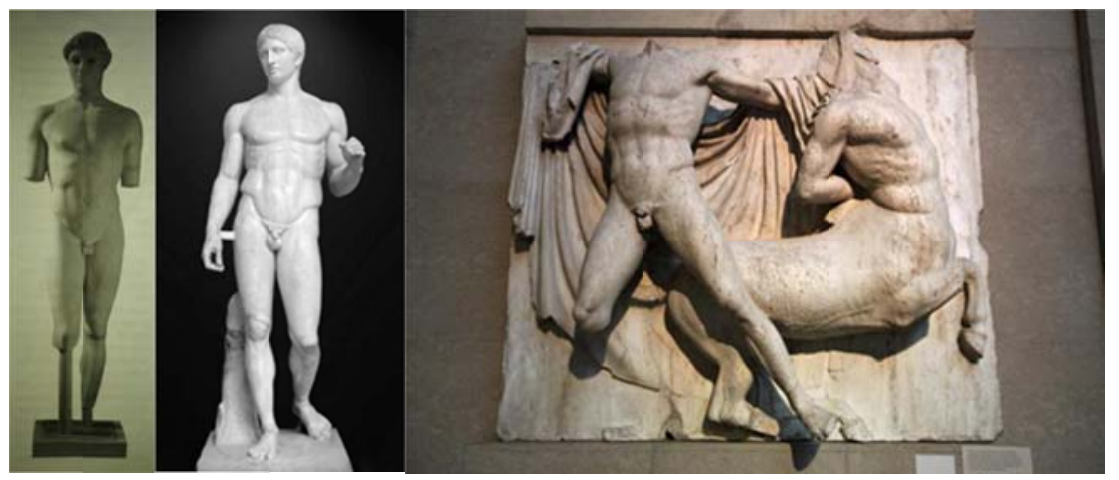

Fig.4, Fig. 5 and Fig. 6

The sculptors worked hard to a real trend of the structure of the human body. The statue standing to approach the true, the body bent, open arms, just perfect dynamic early is powerless to do the sculptor. Miloon's a discus throweris not only a perfect statue of the previous summary, also laid a foundation for the dynamic variety of later sculptors. A discus thrower (Figure 7) showed a moment of action of the athletes in the Olympic Games of ancient Greece discus: human dynamic bending arm formation $\mathrm{S}$. The statue is lateral rotation of the body, legs and separate, not only conforms to the law of motion in the discus, and simple body forms a variety of beauty. A pair of works also showed just perfect human twisted beauty. Injured Niobe's daughter (Figure 8) is a distorted form, due to excessive backward and collapse of the lines of the abdomen. Because of the pain and cannot 
be completely standing posture tells a tragic story to us. Her face was not distorted by pain, but seemed calm. The two statue as a transitional history expression from the rigid stance to the scene of the perfect interpretation of the various postures of the human body is an expression of how accurate. It has laid a good foundation for the later creation of various attitudes of sculptors.

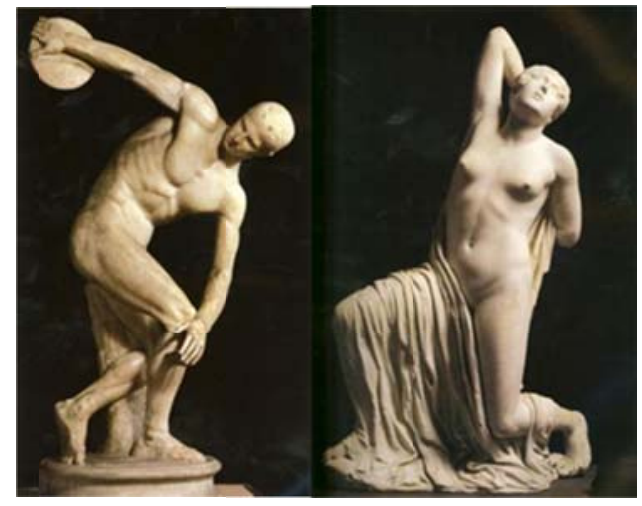

Fig. 7 and Fig. 8

\section{Perfect combination of postures of human bodies and plot of stories}

The saying of that each one has its own merits is the characteristic of the late sculpture. The themes of depicting the inner character of the activities are different. They convey the feelings of the characters in a realistic way. The sculpture of this period has a very rich style, and the statue of the dynamic posture, static posture and group of the form of a large number, including some of the characteristics of a particularly exaggerated statue. The group statue Laocoon(Figure 9) the purpose is very clear. So many dramatic characters and the expression of horror and expression of pain and passion are intertwined. The sculpture of the young goose by Greek sculptor Hal Keaton (Figure 10) depicts a lively child and a goose play scene. The picture is not only full of childlike, children's image also depict very vivid and interesting. The child desperately want to go ahead and pull back the goose, the goose is hard to compete with the kick. The sculpture is extremely rich in life. The statue of the children and goose slapstick scenes shows a vivid postureand a reasonable relationship between goose and child.

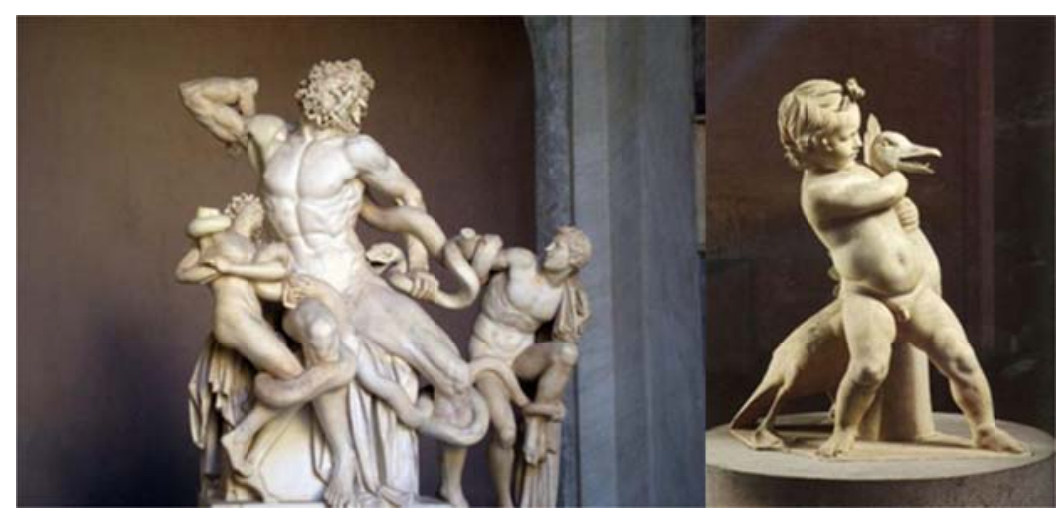

Fig. 9 and Fig. 10 


\section{Conclusion}

From the perspective of the early human bodies, the ancient Greek statue mainly referred the ancient Egyptian statues without its own style. But in the middle ages, the ancient Greek sculpture has gradually form edits own style. The standing postures of human bodies often had a story plot. When the sculpture developed to the late period, the ancient Greek sculptors are more concerned about the performance of human nature. Every piece of work has a profound meaning. We should not only inherit the spirit of the ancient Greek sculpture, but also promote the development of sculpture art with innovation.

\section{References}

[1] Susan Woodford, The Cambridge Introduction to Art: The Art of Greece and Rome, Yilin Press: Nanjing, pp. 11-13, 2009.

[2] John Griffiths Pedle, Greek Art and Archaeology, Guangxi Normal University Press: Guilin, pp. 36-37, 2005.

[3] F. B. Tarbell, A History of Greek Art, Shanghai People's Publishing House: Shanghai, pp. 5153, 2010.

[4] Fred.S.K, Gardner's Art through the Ages, China Youth Publishing House: Beijing, pp. 121-122, 2007. 